\title{
New generation of energy design tools for low impact buildings
}

\author{
B. Mirani \& L. Mahdjoubi \\ School of Built and Natural Environment, \\ University of the West of England, UK
}

\begin{abstract}
The thrust of research in the last decades has sought to develop and enhance lighting and energy simulation tools to achieve low impact buildings (LIB). Recent efforts involved the integration of these simulation tools with computed aided design (CAD) tools to ensure a better adoption of software by the design community. Despite these efforts and the availability of a myriad of tools, emerging evidence suggests that progress in lighting and energy simulation did not have a significant impact on the way designers work to deliver LIB. Design teams still view energy performance goals as a compliance issue that can be addressed later on in the tuning process. This paper reports on a study, which sought to establish the suitability of the level of accuracy, data input and fitness for purpose, for each stage of the design process, of three families of new generations of lighting and energy design tools for LIB. The potentials and limitations of emerging lighting and energy simulation tools to support specific energy design requirements are examined. The implications on research and software development for low impact buildings are also discussed.
\end{abstract}

Keywords: lighting and energy simulation, energy design tools, low impact buildings (LIB), computer aided design (CAD), architects.

\section{Background}

Fundamental design decisions taken early in the design process have far reaching environmental impacts later on. It is widely acknowledged that "all the big mistakes are made on the first day of the design process" [1]. In the current practice most of the environmental design decisions are taken late in the design process to validate design after critical decisions have already been made $[2,3]$. 
"The building form, orientation, fenestrations and construction materials are often decided early in the design by architects with little or no support" [4]. These issues have important implications in achieving the low impact building agenda.

Yet, buildings represent $45 \%$ of all carbon emission and therefore, it is imperative that carbon reductions are made in the construction sector to achieve these goals [5]. Much concern is expressed among building professionals to minimise detrimental effects of construction in wake of challenges posed by changing climatic conditions [6-9].

It is increasingly being acknowledged that to address these challenges, a fundamental change to designers approach in designing LIB is needed. Consequently, the industry is challenged to deliver a variety of tools in the design for LIB [4, 10-12], including energy and lighting software. These tools need to be integrated with the way designers think and work, before they become fully embedded in the design decision-making.

\subsection{Integration between LIB tools and the design process}

Available evidence suggests that conventional design tools do not effectively communicate environmental impact of design decisions between concerned parties $[13,14]$. This limitation has inhibited designers in evaluating lighting and energy performance of building design when it matters most. Conventional LIB tools have been developed in research domains by specialists, software developers and product manufacturers to address a particular specialism of building design $[10,13,15]$. Consequently, they often pay little or no regard to the whole design process.

Despite the availability of sufficient technology, lighting and energy analysis tools have proven to be incompatible with the design process [5, 16-18]. For example, detail of data input required by many of these tools is not consistent with the nature of design information available at that stage. Building performance simulation is mostly executed after design stage and thus does not sufficiently integrate in design decision making [19]. Steemers [20] argued that "any tool that requires more detail input is of little value, because to generate such data, the decisions would already have to be made."

Lighting and energy simulation tools are often complicated to use and decisions regarding energy performance are often outsourced [15, 17, 21]. Most of them require extensive training in their use and a thorough understanding of the domain they address. For example, energy assessment tools for heating, ventilation and air conditioning (HVAC) and lighting not only require training in the use of tools (e.g. Autodesk Ecotect, IES VE etc.), but they also need a good understanding of each area of specialism (i.e. daylighting, natural ventilation). The fundamental issue is that LIB tools and design tools are not easily integrated with each other. CAD packages and LIB tools see building design differently [2]. Most design and LIB tools are characterised with barriers in data exchange and/or interoperability [16, 17]. Designers/consultants are often required to reiterate building design within LIB tools at later stages, which leads to rework, waste of time and effort and, above all, widens the gap between design 
disciplines. The lack of fitness between tools restricts architects to produce alternative design solutions, based on what if lighting and energy building performance scenarios.

Clearly, there has been an increasing pressure for an improved integration between design and LIB tools to facilitate and foster the evaluation of various stages of the design process. Some of the emerging commercial tools, such as the Integrated Energy Simulation Virtual Environment (IES VE), Autodesk Ecotect (AE), EnergyPlus (EP) have sought to address this issue.

Despite the drive to integrate with the design process, designers are still required to have an understanding of the domain these LIB tools seek to address. It can also be implied that to address integration issues, the designers are burdened with learning another way of defining building geometry within computer based tools. Research indicate that design teams still view energy performance goals as a compliance issue that can be addressed in the tuning process and there has been no fundamental change in the design process [3]. Despite the availability of a myriad of LIB tools, there is evidence to suggest that they have failed to assist designers and decision makers to deliver LIB [13].

\subsection{Recent developments in LIB tools and design decision-making}

Various approaches have been adopted by developers to integrate CAD tools with LIB tools. Some efforts sought to facilitate building energy and lighting evaluation at the early stages of the design process. Software plugin-support was the most common approach adopted by developers to enable designers to perform energy and lighting analysis from a CAD environment (e.g. IES VE toolbar in Google SketchUp).

Another approach sought to incorporate Building Information Modelling platform to 'import' and 'export' design file formats from CAD package (Autodesk Revit) to a web based energy assessment tool (Green Building Studio) and later on to a standalone desktop energy analysis tool (Autodesk Ecotect).

These developments in the new generations of LIB tools are fairly recent, and therefore, it has not been established yet the fitness of these tools for designers' decision-taking purposes at various stages of the design process. This paper reports on a study designed to examine whether the new generation of LIB tools are adequate to support the various stages of design process.

\section{Methodology}

This research used a mixed approach involving eliciting practitioners' responses to the suitability of most prevailing approaches to commercial LIB, at various stages of the design process. Using real-life examples from three emerging approaches to LIB software, designers were asked to determine the suitability of the specific approach, for a particular stage of the design process, according to key criteria; namely level of accuracy, detail of data input, output representation, detail in model definition and fit for purpose. Semi-structured interviews were 
conducted with participants to gauge their awareness and suitability of the LIB tools. Designers' responses were captured using a questionnaire.

Within the scope of research, LIB tools were classified into three broad categories as energy design tools, simple simulation tools and advanced simulation tools. A sample from each of these three families of LIB tools were presented to designers for evaluation of suitability for four stages of the design process; namely site planning/feasibility, outline design, scheme design, and detail design. The following tools were evaluated in this study:

- Lighting and Thermal (LT) method developed by Martin Centre for Architectural and Urban Studies, Cambridge, was chosen from the family of Energy design tools, as it is specifically designed to help architects perform energy evaluation at early stages of the design process. Although the LT method is not very widely used yet in practice, it was deemed appropriate for evaluation as it seeks to enable designers to evaluate energy performance at the early design stages.

- $\quad$ Autodesk Ecotect (AE) was selected from the family of simulation tools as it is one of the very few LIB tools that provide integration with computer based design and drafting tools (Revit platform). Altavilla et al. [22] compared 16 energy analysis tools for applicability and use among engineers and designers and found out that AE was the only LIB tool used specifically by designers. Additionally, the Autodesk stressed that that tool is primarily developed to assist designer perform simulation exercise at various stages of the design process [23].

- Integrated Energy Simulation Virtual Environment (IES VE) was also chosen from the family of advanced simulation tools, as it provides integrated energy simulation for various energy performance criteria and is commercially available. This LIB tool was particularly chosen because of its recent integration with Google SketchUp. IES VE toolbar is provided within Google SketchUp, which allows simulation exercise to be performed from SketchUp User Interface. This is a different approach adopted from other plugin software that have focussed on developing compatible file formats for importing and exporting to different software environments.

Responses from 23 designers were sought. Each participant was presented with the three samples of tools; LT Method, AE and IES VE. Participants were asked to rate LIB tools for required level of accuracy, right detail of data input, and fit for purpose etc., at each design stage. The research focused on tasks and activities that the designers typically carried out in each design stage to establish the suitability of solutions with the way designers worked in practice to produce design for LIB, at a specific stage of the process.

\section{Results}

\subsection{Level of accuracy}

The research revealed that higher levels of accuracy derived from sophisticated tools belonging to the family of simulation (AE) and advanced simulation tools 
(IES VE) was not essential at site planning/feasibility stage. It was proposed that approximation showing the trends of energy consumption of heating, lighting and cooling loads, given by energy design tools (LT method) was more appropriate. As the building design progressed from the early design stage to scheme and detail design stages, more and more accuracy was considered important to evaluate energy performance, and accurately predict environmental impact on building design.

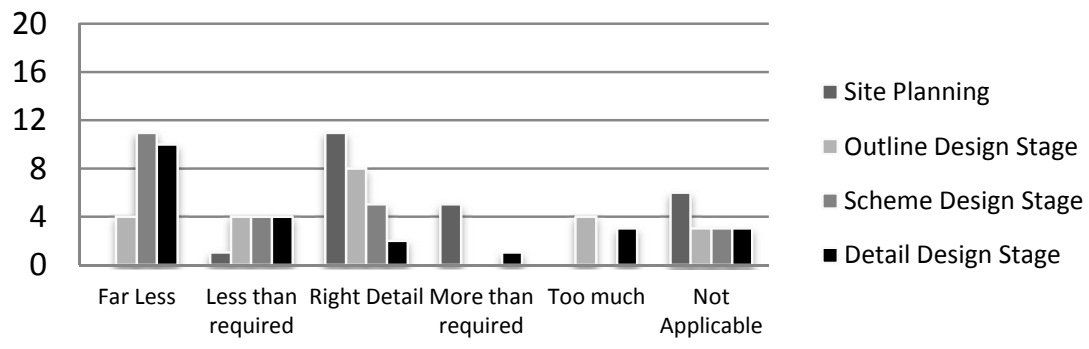

Figure 1: $\quad$ Levels of accuracy for LT method.

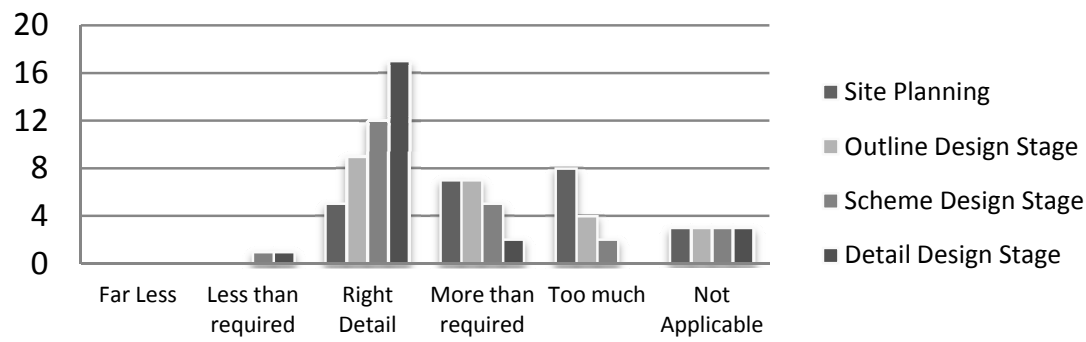

Figure 2: $\quad$ Levels of accuracy for Autodesk Ecotect.

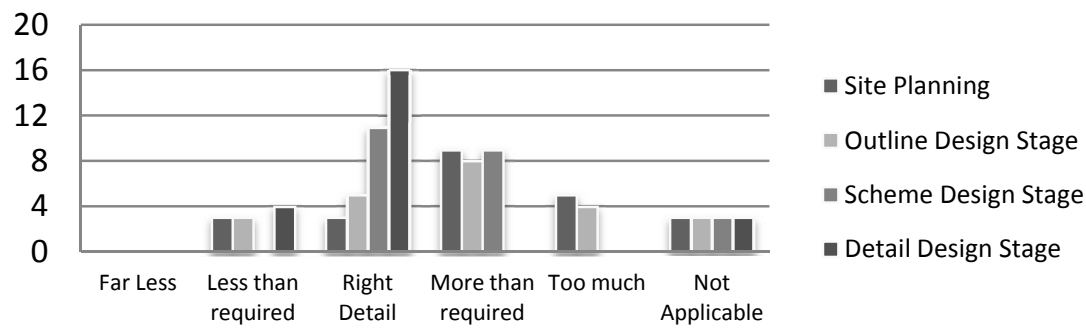

Figure 3: $\quad$ Levels of accuracy for IES VE.

\subsection{Data input}

The detail of data input required by sophisticated LIB tools was found to be more than necessary during site planning/feasibility stage and outline design 
stage. This implied that the detail of data input required by tools to perform energy evaluation was not in tune with the nature of information regarding design parameters at hand during this stage of the design process. A consensus failed to emerge regarding right detail of data input even at scheme design stage when building design is nearly fixed. Consequently, it may be possible that LIB tools are required to demand the right detail of data input pertaining to the stage of the design process and in tune with specific design parameters that are assessed at that stage.

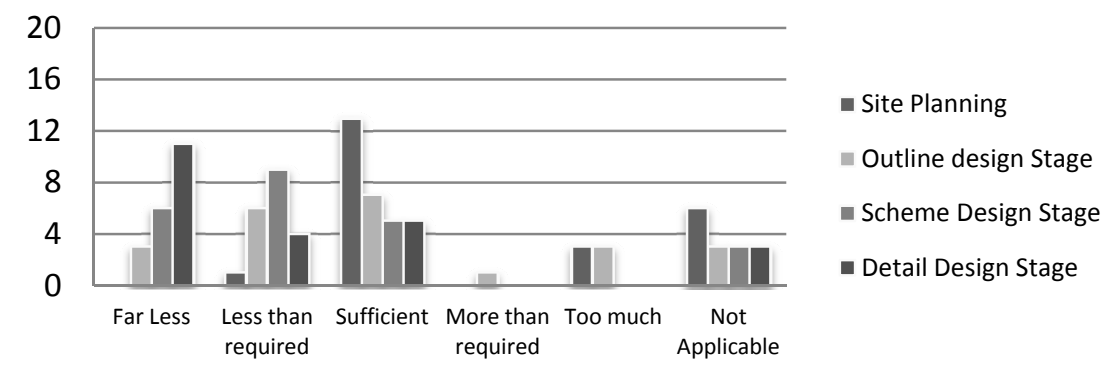

Figure 4: Detail of data input for LT method.

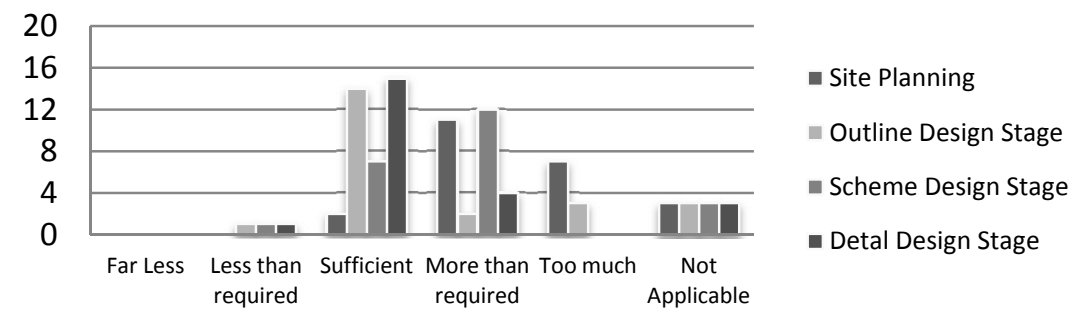

Figure 5: Detail of data input for Autodesk Ecotect.

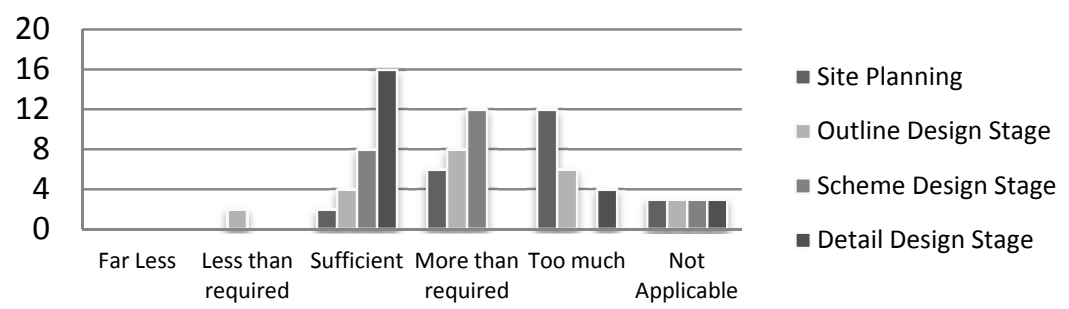

Figure 6: Detail of input data for IES VE.

\subsection{Fit for purpose}

The findings revealed that simple Energy design tools compared to others were fit for purpose at early design. However, because of limitations in output 
representation and interoperability issues, they were not preferable. Simulation and advance simulation tools were considered inadequate, at the early stages of the design and better fit for purpose at detail design stage, when most of the building design is complete. There was also an understanding that simulation tasks were undertaken by engineers in the later stages, and that designers can never be mechanical and electrical engineers [13].

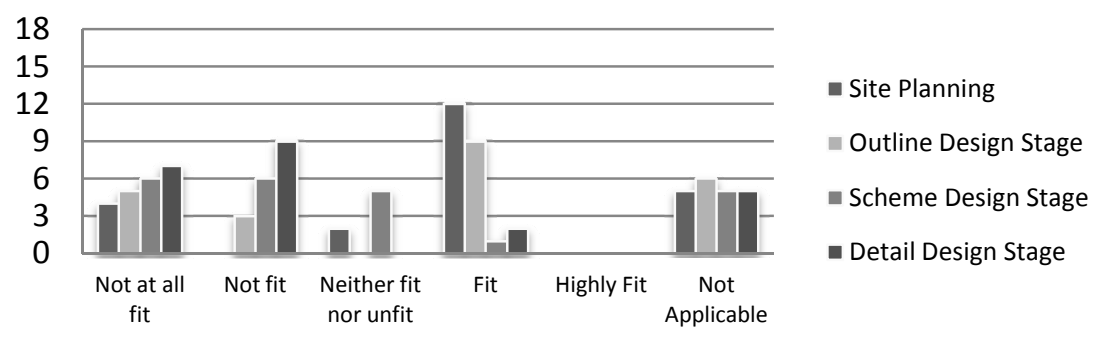

Figure 7: $\quad$ Fit for purpose- LT method.

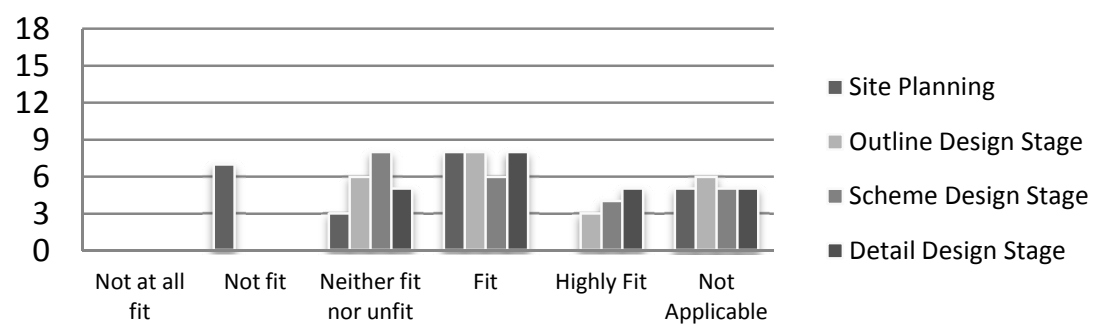

Figure 8: $\quad$ Fit for purpose- Autodesk Ecotect.

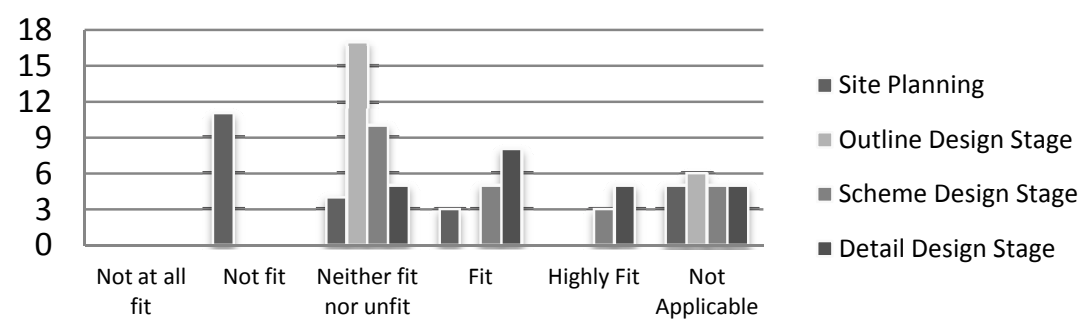

Figure 9: $\quad$ Fit for purpose- IES VE.

\subsection{Suitability of output representation}

The output representation in terms of energy costs and annual energy consumption in figures given by the energy design tool (LT method) and simulation tool (AE), was appreciated at site planning/feasibility stage. Visual 
output representation by the simulation tool (AE) was found to be suitable for designers to interpret the trends in different simulation exercises at outline design stage. The output options (numbers, graphs, tables, and visuals) provided by the sophisticated LIB tool (IES VE) were found most suitable at scheme and detail design stages. A number of other factors were found to influence designers' output preferences, such as background, experience and understanding of the domain of energy analysis. Therefore, LIB tools are required to represent outputs in different formats to provide flexibility to users, to determine their preferred option.

\subsection{Detail in model definition}

Detail in model definition was also discovered to relate to data sharing and interoperability issues. The sample of LIB tools were carefully selected to obtain responses from designers regarding different approaches adopted by developers of LIB tools to address these issues. Although, respondents preferred the simple 'passive and non-passive' model definition of energy design tools in early design stage, but inflexibility to expand the model definition of the same design for later stages was not desirable. Consequently, flexibility of model definition (spaces as single zone and each room individually) provided by simulation tools integrated with a CAD based platform received the most positive response.

It emerged that most designers may prefer defining spaces in a CAD platform and exporting it to another platform to perform a simulation exercise, rather than defining geometry within simulation tools. However, the approach adopted to resolve data exchange and interoperability issues between the CAD platform and LIB tools was considered fraught with problems. Respondents reported that importing and exporting files was not an easy task.

\section{Discussion of results}

During the interviews, many respondents reported that they have heard of plugin support and integration between the various tools, especially Autodesk Ecotect with Revit platform, but only few were aware of the extended functionality of CAD with LIB tools. However, most participants had not heard of the LT method.

\subsection{Site planning/feasibility stage}

It was found that at the site planning/feasibility stage, the LT method was considered suitable in terms of giving sufficient levels of accuracy, requiring the right detail of data input according to the nature of design information at hand. For example, it can provide annual energy consumption per square meter of floor area. However, in terms of output representation, numerical units of energy consumption per annum for a given space was considered inappropriate, as explained by one of the designers, "Designers are visual and spatial beings responding to information, it's not about definitive figures...that's not the way to communicate best with designers." 
AE was preferred for output representation as it provides energy costs and water costs in figures (Green Building Studio), and visual outputs to communicate design information. However, the responses suggested that $\mathrm{AE}$ and IES both require more data input to define building geometry and produced higher levels of accuracy, which were not essential at this stage.

With regard to IES and AE, a senior architect explained that, "...the whole system is not good for site planning/feasibility stage but output representation is visual, something that designers can respond to." Generally, most of the new generation of LIB tools were not appropriate for this stage of the process.

\subsection{Outline design stage}

LT method received mixed responses for levels of accuracy and detail of data input to evaluate energy performance of building design at outline design stage. It was perceived favourably for its emphasis to enable designers to evaluate buildings' energy performance at the early stages. For instance, it was reported that "the whole package is good for making broad strategic decisions, even if it is clunky to use at least one can compare things like glazing ratio etc." However, it was judged limited in output representation, "it could have been brilliant if it were more responsive to manipulating $3 D$ models, figures and things that you are evaluating and gave corresponding results."

AE was considered sufficiently accurate and gave suitable output by providing good design information and options that enabled designers make design decisions. However, detail of data input required undertaking such an analysis was considerate as burdensome. The data input required and output representation by IES received mixed responses, possibly related to designers' individual preferences.

It is important to note that about a third of participants did not consider any of the tools fit for purpose at outline stage. It can be implied that despite the latest software solutions provided for designers to integrate energy simulation in terms of data sharing and interoperability, the tools are still not fit for purpose at the early stages of the design process.

\subsection{Scheme design stage}

At scheme design stage, the use of LT method for energy evaluation was problematic. This is not surprising as this tool was essentially developed to assist designers in the early stages of the design process. At this stage, the preferred design is developed in a more detail manner and more design information is available to perform a simulation exercise.

However, about a quarter of the respondents felt that the detail of data input required by $\mathrm{AE}$ was more than required. Mixed responses were recorded for IES. The visual output backed by numerical data given in AE and IES for the different analysis is much preferred at this stage. However, a clear pattern to indicate fit for purpose could not be determined.

There was much discussion with participants over the role of designers and the need to draw boundaries between $\mathrm{M}$ and $\mathrm{E}$ (mechanical and electrical) engineers and themselves, "architects will never be $M$ and E's" [13]. 
Suggestions were made to distinguish between design parameters that can be evaluated for energy performance by designers and others that require engineers and cannot be performed by designers. It was reported that "if we can perform evaluation for lighting, air tightness, natural ventilation and maybe thermal performance...that would be fantastic". Giving an example, to emphasise why designers are concerned with these performance parameters, a participant suggested that "the engineers suggested bigger fenestrations to get the right proportion of lighting...but the Planners will be nervous...especially in designated conservation areas."

\subsection{Detail design stage}

The responses suggested that AE and IES are more suitable for detail design stage, as compared to the other stages. Whether it is for levels of accuracy, detail of input required, suitability of output or fit for purpose, both the tools recorded more acceptable responses, suggesting that they are more adequate for use in the detail design stage.

Scherer [13] indicated that their company, White Design, would want to undertake simulation exercise in-house to evaluate design parameters regarding lighting, thermal performance, air tightness and natural ventilation, "to test every little change in the design for example roof light angle, we have to revert back to the engineers which is not only time consuming but also expensive."

The respondent further indicated that thermal modelling is the most expensive and can be afforded to be done only once in any project, "...however, if we had this tool which was not complicated and easy enough to use, it would be fantastic". He stressed upon getting the fundamentals of design right in the early stages, "one would achieve higher assessment ratings on account of good design automatically". Rather than depending upon renewable technology and other means for carbon reduction after the building design is nearly complete. The company work very closely with mechanical and electrical engineers right from the early stages, "we involve $M \& E$ 's from early stages to not make design errors and pay for it later".

From the results it may be inferred that designers preferred different LIB tools for different criteria at different stages of the design process. This stresses the point revealed review that LIB tools need to relate to the way designers work in practice to produce design for LIB. It is worth mentioning that a discussion with participants led to a debate on the tasks that designers are burdened with. They firmly believed that energy performance evaluation of building design should be undertaken by engineers alone. One of them said, "How much can a designer $d o$ ?" However, as indicated above, involving mechanical and electrical engineers from the early stages and working as an integrated team may be the right approach in the design for LIB.

\section{Conclusion}

The findings of this study suggest that designers preferred different LIB tools for different criteria at different design stages. None of the tools were preferred for 
all the criteria at any stage. They confirmed that designers are required to design buildings in a way that fit in with the needs of LIB tools to perform tasks, rather than LIB tools supporting designers in the way they work and design buildings in practice. Perhaps, this may be the fundamental reason for low uptake of LIB tools by designers as indicated in the research.

Although much progress has been made to address data sharing and interoperability issues by the new generation of LIB tools, but it seems that effort are inadequate to respond to the architects' concerns to deliver the design for LIB. The research suggested that despite the advances in approach, increasing functionality and scope of the new generation of LIB tools, they are still inadequate in many respects to support designers in the way they work and think.

Further research is needed to evaluate the adequacy of LIB tools with respect to specific design tasks (lighting, ventilation, thermal modelling etc.) at various design stages. This may provide a more structured guidance and support for the development of the new generation of LIB tools.

\section{References}

[1] Lovins, A., In: Dunsdon, A., Day, A., Jones, P., Towards a computer based framework to support the low carbon building design process. International Journal. Low-Carbon Technology. 1(4), pp. 355-371, 2006.

[2] Dunsdon, A., Day, A., Jones, P., Towards a computer based framework to support the low carbon building design process. International Journal. Low-Carbon Technology. 1(4), pp. 355-371, 2006.

[3] Wagner, S. and Mellblom, P., The next generation of energy efficient building design: where are we and where should we be going? Online. http://www.thebestconference.org/best1/pdfs/016.pdf

[4] Hong, T., Chou, S., Bong, T., Building Simulation: An overview of developments and information sources. Building and Environment, 35(4), pp. 347-361, 2000.

[5] Lowe, R., Defining and meeting carbon constraints of $21^{\text {st }}$ century. Building Research \& Information, 28(3), pp. 159 - 175, 2000.

[6] Johnson, S., Greener Buildings: Environmental impact of property. Basingstoke, Hampshire: Macmillan.1993.

[7] Cole, R.J., Building environmental assessment methods: clarifying intentions. Building Research \& Information, 27(4 \& 5), pp. 230-246, 1999.

[8] Crawley, D., and Aho, I., Building environment assessment methods: application and development trends. Building Research \& Information, 27(4 \& 5), pp. 300-308, 1999.

[9] Hyter, S., Hyter, R., Judkof, R., Torcellini, P., The Energy Design Process for Designing \& Constructing High-Performance Buildings, 2001 Online. http://www.engg.ksu.edu/people/rhayter/CLIMA2000.pdf

[10] Papamicael, K., Porta, J. and Chauvet, H., Building Design Advisor: automated integration of multiple simulation tools. Automation in Construction, 6(4), pp.341-352.1997. 
[11] Morbitzer, C., Strachan, P., Webster, J., Spires, B., Cafferty, D., Integration of Building Simulation into the Design process of an Architecture practice. Proc. $7^{\text {th }}$ International IBPSA Conference, Rio de Janeiro, 13-15 August, 2001.

[12] Ellis, P., Torcillini, P. and Crawley, D., Energy Design Plugin: An EnergyPlus Plugin for SketchUp Online. http://www.nrel.gov/docs/ fy080sti/43569.pdf

[13] Technology Strategy Board, Low Impact Buildings. Innovation Platform, Online.http://www.innovateuk.org/ assets/pdf/LowImpactBuildingsIPSept0 $\underline{9 . p d f}$

[14] Scherer, T., Personal Communication, 15 March 2010, Senior Architect, White Design. Bristol, U.K.

[15] Attia, S., Beltrán, L., De Herde, A. and Hensen, J., Architect Friendly: A comparison of ten different building performance simulation tools. Proc. $11^{\text {th }}$ International IBPSA Conference, Building Simulation, Glasgow, 2009 Online. http://www.ibpsa.org/proceedings/BS2009/BS09_0204_211.pdf

[16] Morbitzer, C., Towards the Integration of Simulation into the Building Design Process. Chapter 3: The simulation supported design process. University of Strathclyde, 2003 Online. http://www.esru.strath.ac.uk/ Documents $/ \mathrm{PhD} /$ morbitzer thesis.pdf

[17] Hensen, J., Towards more effective use of building performance simulation in design, Proc. 7th International Conference on Design \& Decision Support Systems. Architecture and Urban Planning, Technische Universiteit Eindhoven, 2-5 July, 2004.

[18] Brahme, R., O’Neill, Z., Sisson, W. and Otto, K., Using Existing Building Energy Tools For Designing Net-Zero Energy Buildings-Challenges and Workarounds. Proc. $11^{\text {th }}$ International IBPSA Conference Building Simulation, Glasgow, July 27-30, 2009.

[19] Schlueter, A. and Thesseling, F., Building information model based energy/exergy performance assessment in early design stages. Automation in Construction, 18(2), pp.153-163, 2008.

[20] Steemer, K., Energy Tools for Designers. Building Research Establishment, Proc. BEPAC Conference, Building Environmental Performance - Facing the Future, University of York, UK, pp.123-128, 1994.

[21] Hobbs, D., Morbitzer, C., Spires, B., Strachan, P., Webster, J., Experience of using Building Simulation within the design process of an Architectural Practice. Proc. $8^{\text {th }}$ International IBPSA Conference, Building Simulation Eindhoven, 11-13 August, 2003.

[22] Altavilla, F., Vicari, B., Hensen, J. L. M., and Filippi, M., Simulation tools for building energy design. Proc. 7th International Conference on Design $\&$ Decision Support Systems, Architecture and Urban Planning, Eindhoven, 2004.

[23] Autodesk, Ecotect Analysis, Using Autodesk Ecotect Analysis \& BIM, White Paper Online.http://images.autodesk.com/adsk/files/using_autodesk ecotect_analysis_and_building_information_modeling_final.pdf 